\title{
Isolation, biochemical characterization, and cloning of a bacteriocin from the poultry-associated Staphylococcus aureus strain CH-91
}

\author{
Benedykt Wladyka $\cdot$ Katarzyna Wielebska • \\ Marcin Wloka • Oliwia Bochenska • Grzegorz Dubin • \\ Adam Dubin • Pawel Mak
}

Received: 29 August 2012/Revised: 5 November 2012 / Accepted: 7 November 2012/Published online: 30 November 2012

(C) The Author(s) 2012. This article is published with open access at SpringerLink.com

\begin{abstract}
Staphylococcus aureus strain CH-91, isolated from a broiler chicken with atopic dermatitis, has a highly proteolytic phenotype that is correlated with the disease. We describe the isolation and biochemical and molecular characterization of the AI-type lantibiotic BacCH91 from $S$. aureus $\mathrm{CH}-91$ culture medium. The bacteriocin was purified using a three-stage procedure comprising precipitation with ammonium sulfate, extraction with organic solvents, and reversed-phase HPLC. The BacCH91 peptide is thermostable and highly resistant to cleavage by both prokaryotic and eukaryotic peptidases. The MIC for the Gram-positive bacteria ranged from $2.5 \mathrm{nM}$ for Microococcus luteus through 1.3-6.0 $\mu \mathrm{M}$ for staphylococcal strains up to more than $100 \mu \mathrm{M}$ for Lactococcus lactis. BacCH91 was ineffective against the Gram-negative strains tested at the maximal concentration $(100 \mu \mathrm{M})$. The amino acid sequence of BacCH91 is similar to that of epidermin and gallidermin. The encoding gene (bacCH91) occurred in two allelic variants distinguishable in the restriction fragment length polymorphism assay. Variant I, identified in S. aureus CH-91, dominated in $S$. aureus strains of poultry origin, although
\end{abstract}

Electronic supplementary material The online version of this article (doi:10.1007/s00253-012-4578-y) contains supplementary material, which is available to authorized users.

B. Wladyka $\cdot$ K. Wielebska $\cdot$ M. Wloka $\cdot$ O. Bochenska

A. Dubin $\cdot$ P. Mak $(\bowtie)$

Department of Analytical Biochemistry, Faculty of Biochemistry,

Biophysics and Biotechnology, Jagiellonian University,

Gronostajowa 7,

30-387 Krakow, Poland

e-mail: pawel.mak@uj.edu.pl

G. Dubin

Department of Microbiology and Malopolska

Centre of Biotechnology, Faculty of Biochemistry, Biophysics

and Biotechnology, Jagiellonian University, Gronostajowa 7,

30-387 Krakow, Poland strains with variant II were also identified in this group. $S$. aureus strains of human origin were characterized exclusively by variant II.

Keywords Allelic variant - Bacteriocin · Lantibiotic · Staphylococcus aureus $\cdot$ Pathogen $\cdot$ StpC cysteine peptidase

\section{Introduction}

Staphylococcus aureus is a common opportunistic pathogen of humans and other warm-blooded animals. The bacterium is responsible for a variety of infections, constituting an important veterinary and public health issue associated with a substantial economic burden. The increasing antibiotic resistance of this bacterium is of major concern and has prompted studies on its pathophysiology.

Despite their broad host diversity, adaptation of individual strains to particular hosts occurring by acquisition of hostspecific gene pools and/or loss of dispensable genetic material has been suggested in recent studies (Herron-Olson et al. 2007; Lowder et al. 2009). S. aureus strain CH-91 was initially isolated from a broiler chicken with atopic dermatitis (Kuramasu et al. 1967). The disease was correlated with a highly proteolytic phenotype (Takeuchi et al. 2002) associated with a 17-kb plasmid (pCH-91) that is homologous to the poultry-associated pAvX plasmid (Lowder et al. 2009). Both plasmids encode cysteine peptidase staphopain C (StpC), an avian host-specific virulence factor (Wladyka et al. 2011a).

Bacteria produce a wide variety of bioactive peptides, which among many other factors facilitate their environmental success. One of the important functions of bioactive peptides is the modulation of interactions with co-occurring organisms, most importantly the host and potential competitors. Staphylococci secrete a wide range of peptides involved in deregulation of the host immune response (Dinges et al. 2000; Foster 2005; Postma 
et al. 2004). The range of secreted peptides varies among strains, and some profiles correlate with a virulent phenotype (Wang et al. 2007). Bacteria produce a diverse range of polypeptides involved in both inter- and intra-species interactions. Among these, bacteriocins are peptides directed against a variety of bacteria; hence, they are of special interest, given their potential use in medicine and the food industry (Galvez et al. 2007; Gillor and Ghazaryan 2007). Staphylococci provide a rich source of diverse bacteriocins. To date, five such peptides (Pep5, epidermin, epicidin 280, epilancin K7, and epidermicin NI01) have been characterized from Staphylococcus epidermidis (Heidrich et al. 1998; Kaletta et al. 1989; Sandiford and Upton 2011; Schnell et al. 1988; van de Kamp et al. 1995). Among other bacteriocins, gallidermin was isolated from Staphylococcus gallinarum (Kellner et al. 1988), hominicin was isolated from Staphylococcus hominis (Kim et al. 2010), and nukacin ISK-1 was isolated from Staphylococcus warneri (Sashihara et al. 2000). Strains of $S$. aureus have also been shown to produce bacteriocins, including the two-peptide lantibiotic staphylococcin C55 (Navaratna et al. 1998), the closely related staphylococcin BacR1 (Crupper et al. 1997), the tryptophan-rich aureocin A53 (Netz et al. 2002, 2001), and aureocin A70. Contradictory reports exist concerning the presence of epidermin homologues in S. aureus (Daly et al. 2010; Joo et al. 2011). Intriguingly, with the exception of gallidermin, the genes encoding the bacteriocins noted above are located on plasmids, often together with genes determining antibiotic resistance or encoding virulence factors.

Here, we describe the isolation and biochemical characterization of bacteriocin BacCH91 from S. aureus strain CH-91 and show for the first time the ability of $S$. aureus to produce the epidermin-like lantibiotic. Cloning of the encoding gene bac $\mathrm{CH} 91$ and a comparative sequence analysis facilitated identification of a unique allelic variant of bacCH91 associated with S. aureus strains originating from poultry.

\section{Materials and methods}

Bacterial strains and growth conditions

S. aureus CH-91 was kindly provided by S. Takeuchi from Fukui Prefectural University, Japan (Takeuchi et al. 1999). The strain has been deposited in the DSMZ collection under the number DSM 26258. Bacillus licheniformis NCTC 7224, Bacillus subtilis ATCC 6633, Lactococcus lactis subsp. lactis LOCK 0869, Micrococcus luteus strains DSMZ 20030 and CBM (clinical isolate), Sarcina lutea ATCC 9341, S. aureus strains ATCC 25923, M-122 (Polakowska et al. 2012), Newman and RN4220, S. epidermidis ATCC 35347, Staphylococcus intermedius ATCC 29666, Staphylococcus pseudintermedius LMG 22219 (Devriese et al. 2005), Staphylococcus saprophyticus ATCC 49453, Staphylococcus xylosus strains isolated from the skin of healthy chickens, Streptococcus mutans ATCC 25175, Streptococcus pneumoniae ATCC 49619, Escherichia coli K12 ATCC 10798, Klebsiella pneumoniae, Serratia marcescens, and Sphingomonas sp. AMC 3962 (Dziga et al. 2012) were obtained from the collections of The Faculty of Biochemistry, Biophysics and Biotechnology, Jagiellonian University, Krakow, Poland. A list of strains used for assessment of the general occurrence of the bacteriocin gene is provided in the Electronic supplementary materials (ESM; Table S1). Gram-positive and Gram-negative bacteria were maintained at $37^{\circ} \mathrm{C}$ in tryptic soy broth (TSB) and LuriaBertani broth (both obtained from Sigma), respectively. To determine the minimal inhibitory concentration (MIC) doses, all bacteria were cultivated in cation-adjusted Mueller-Hinton broth (MHB, Sigma) or, in the case of Streptococcus spp. and L. lactis, grown on agar-solidified MHB supplemented with $2.5 \%$ lysed horse blood (LHB, Graso).

\section{Purification of bacteriocin}

Bacteriocin BacCH91 was purified from S. aureus $\mathrm{CH}-91$ culture supernatant. The bacteria were cultivated in TSB at $37{ }^{\circ} \mathrm{C}$ and $200 \mathrm{rpm}$ shaking for $18 \mathrm{~h}$. The culture was centrifuged at $17,000 \times g$ for $15 \mathrm{~min}$ at $4{ }^{\circ} \mathrm{C}$. The supernatant was acidified to $\mathrm{pH} 3.0$ using $5 \mathrm{M} \mathrm{HCl}$ and then precipitated with ammonium sulfate to $80 \%$ saturation at $4{ }^{\circ} \mathrm{C}$. The precipitated material was recovered by centrifugation at $17,000 \times g$ for $30 \mathrm{~min}$ at $4{ }^{\circ} \mathrm{C}$. The pellet was dissolved in water and freeze-dried. The resulting dry powder was extracted for $5 \mathrm{~min}$ in a mixture of chloroform and methanol $(2: 1, v / v)$ with vigorous shaking at room temperature (RT). The extract was clarified by centrifugation $(13,000 \times g$ for 5 min at RT). The clear supernatant was removed and dried in a centrifugal evaporator. The dry extract was dissolved in water containing $27 \%(v / v)$ acetonitrile and $0.09 \%(v / v)$ trifluoroacetic acid (TFA), and the resulting preparation was filtered through a $0.45-\mu \mathrm{m}$ centrifugal filter and subjected to high-performance liquid chromatography (HPLC) separation on a LC-8 column $(150 \times 4.6 \mathrm{~mm} ; 3 \mu \mathrm{m}$ particle size; Supelco $)$ using a buffer system comprising buffers A $(0.1 \%$ TFA; $v / v)$ and B $(0.07 \%$ TFA in $80 \%$ acetonitrile; $v / v)$, with a linear gradient from 40 to $80 \%$ buffer B over $20 \mathrm{~min}$ at $1 \mathrm{ml} / \mathrm{min}$. Fractions containing BacCH91 were detected by measuring absorbance at 220 and $280 \mathrm{~nm}$, collected, dried in a centrifugal evaporator, dissolved in water, and stored at $-20{ }^{\circ} \mathrm{C}$ until further use.

Protein chemistry techniques

Chemical derivatization to enable detection of modified amino acids in the bacteriocin molecule during N-terminal sequencing was performed according to Meyer et al. (1994). In brief, water was evaporated from the BacCH91 solution 
in a centrifugal evaporator. The bacteriocin was re-dissolved in a solution containing $46 \%$ ethanol $(v / v), 10 \%$ ethanethiol $(v / v)$, and $0.5 \mathrm{M} \mathrm{NaOH}$. The preparation was purged with argon and sealed. Following incubation for $2 \mathrm{~h}$ at $50{ }^{\circ} \mathrm{C}$, the preparation was acidified with glacial acetic acid, vortexed, and used for N-terminal amino acid sequencing.

The N-terminal amino acid sequence was determined in an automatic protein sequencer (Procise 491; Applied Biosystems) using Edman degradation of the polypeptide chains. The polybrene-coated glass fiber discs were used for sample immobilization according to the manufacturer's instructions.

Amino acid analysis was performed according to White et al. (1986). In brief, bacteriocin was hydrolyzed in the gas phase over $6 \mathrm{M} \mathrm{HCl}$ at $115^{\circ} \mathrm{C}$ for $24 \mathrm{~h}$. The liberated amino acids were converted to phenylthiocarbamyl derivatives and analyzed by HPLC (PicoTag $150 \times 3.9$ mm column; Waters). The total protein concentration was estimated using the bicinchoninic acid assay (BCA, Sigma).

Electrospray ionization mass spectrometry (ESI-MS) was carried out using an HCT Ultra mass spectrometer (Bruker) equipped with an electrospray source and an ion trap analyzer.

Tris-tricine sodium dodecyl sulfate polyacrylamide gel electrophoresis (SDS-PAGE) was carried out under reducing conditions using peptide-separating gels, according to the protocol of Schagger and von Jagow (1987). Following electrophoresis, the gels were fixed for $30 \mathrm{~min}$ in a mixture of $50 \%$ methanol $(v / v)$ and $10 \%$ acetic acid $(v / v)$, and stained with Coomassie Brilliant Blue R-250.

\section{Determination of MIC doses}

The bactericidal activity of BacCH91 was determined using the micro-dilution method in compliance with Clinical and Laboratory Standards Institute guidelines M7-A7 (CLSI 2006). Briefly, the bacteria were either cultivated in cationadjusted MHB to the early exponential phase or grown overnight on agar-solidified MHB supplemented with $2.5 \%$ LHB in the case of Streptococcus spp. and L. lactis. Subsequently, the bacteria were diluted to $1 \times 10^{6} \mathrm{CFU} / \mathrm{ml}$ either in $\mathrm{MHB}$ or in MHB supplemented with $5 \%$ LHB, in the case of the latter bacteria. Fifty-microliter portions of bacterial suspension were mixed with an equal volume of MHB containing serial twofold dilutions of bacteriocin. After overnight incubation at $37{ }^{\circ} \mathrm{C}$, the optical density (OD) at $600 \mathrm{~nm}$ was measured. The MIC was defined as the minimum bacteriocin concentration for which the increase in OD was not observed compared to uninoculated broth.

Radial diffusion assay

For $\mathrm{pH}$, temperature, and protease resistance assays, the residual activity of BacCH91 was determined using the radial diffusion assay (Lemos Miguel et al. 2008). In brief, plates were prepared containing $200 \times$ diluted overnight culture of $S$. lutea ATCC 9341 in TSB agar $(1 \%, w / v)$. Wells (2.4 mm diameter) were cut in the agar and filled with $10 \mu \mathrm{l}$ of the BacCH91 preparation for testing. Following overnight incubation at $37{ }^{\circ} \mathrm{C}$, the residual activity was measured as the diameter of inhibition zones.

Influence of $\mathrm{pH}$, temperature, and proteases on the activity of BacCH91

To test the pH stability of BacCH91, a water solution of the bacteriocin (final concentration, $30 \mu \mathrm{M}$ ) was evaporated in a vacuum centrifuge and re-dissolved in (a) $100 \mathrm{mM}$ sodium citrate $\mathrm{pH}$ 3.0, 4.0, 5.0, and 6.0; (b) $100 \mathrm{mM}$ Tris- $\mathrm{HCl} \mathrm{pH} 7.0$, 8.0, and 9.0; and (c) $100 \mathrm{mM} 3$-cyclohexylamino-1-propanesulphonic acid-NaOH pH 10.0 and 11.0. The solutions were incubated for $3 \mathrm{~h}$ at RT, and the residual activity of the bacteriocin was determined using the radial diffusion assay. The temperature stability of BacCH91 (30 $\mu \mathrm{M}$ final concentration) was determined in $50 \mathrm{mM}$ Tris- $\mathrm{HCl}$ pH 7.4, $0.15 \mathrm{M}$ $\mathrm{NaCl}$ and $50 \mathrm{mM}$ bis-Tris $\mathrm{pH} 6.4,0.15 \mathrm{M} \mathrm{NaCl}$. The solutions were incubated for 1,6 , and $24 \mathrm{~h}$ at $37,60,80$, and $99^{\circ} \mathrm{C}$. The residual activity of the bacteriocin was determined with the radial diffusion assay using $S$. lutea as an indicator strain.

We evaluated the susceptibility of BacCH91 to proteolysis by aureolysin; staphopains $\mathrm{A}, \mathrm{B}$, and $\mathrm{C}$; V8 peptidase (Biocentrum); bovine alpha-chymotrypsin and TPCK-treated trypsin (Sigma); human elastase and cathepsin G (Biocentrum); pepsin from porcine gastric mucosa (Sigma); and proteinase $\mathrm{K}$ (A\&A Biotechnology). Dried samples of BacCH91 were dissolved to a final concentration of $30 \mu \mathrm{M}$ in the following buffers: $100 \mathrm{mM}$ bis-Tris $\mathrm{pH} 6.4$ or Tris- $\mathrm{HCl} \mathrm{pH} \mathrm{7.5,} \mathrm{each}$ containing $5 \mathrm{mM} \mathrm{CaCl}_{2}$ (aureolysin, chymotrypsin, and trypsin); $100 \mathrm{mM}$ bis-Tris $\mathrm{pH} 6.4$ or Tris- $\mathrm{HCl}$ pH 7.5, each containing $5 \mathrm{mM}$ cysteine hydrochloride and $5 \mathrm{mM}$ EDTA (staphopains A, B, and C); $100 \mathrm{mM}$ bis-Tris $\mathrm{pH} 6.4$ or Tris$\mathrm{HCl}$ pH 7.5 (elastase); $100 \mathrm{mM}$ bis-Tris $\mathrm{pH} 6.4$ or Tris- $\mathrm{HCl}$ pH 7.5, each containing $200 \mathrm{mM} \mathrm{NaCl}$ (cathepsin G); $100 \mathrm{mM}$ bis-Tris $\mathrm{pH} 6.4$ or $100 \mathrm{mM}$ sodium phosphate $\mathrm{pH} 6.4$ and pH 7.8 (V8 peptidase); and $100 \mathrm{mM}$ sodium citrate $\mathrm{pH} 3.2$ (pepsin). The peptidases were added in the ratio 1:20 (enzyme/ bacteriocin) by weight, and the mixtures were incubated for $1 \mathrm{~h}$ at $37^{\circ} \mathrm{C}$. The residual activity was determined with the radial diffusion assay using $S$. lutea as an indicator strain, and the bacteriocin molecule integrity was assessed using HPLC.

All of the above experiments were performed in triplicate. The final results are presented as means $\pm \mathrm{SD}$.

Influence of StpC on biosynthesis of BacCH91

S. aureus $\mathrm{CH}-91$ was cultured at $37^{\circ} \mathrm{C}$ in TSB supplemented with the cysteine peptidase inhibitor E-64 (1-[N-[(L-3-trans- 
carboxyoxirane-2-carbonyl)-L-leucyl] amino]-4-guanidinobutane; Sigma) at final concentrations of 1.0, 0.1, and $0.01 \mathrm{mM}$. Aliquots were removed at 5, 10, and $24 \mathrm{~h}$, and the bacteriafree supernatants were obtained by centrifugation.

To estimate the level of BacCH91, the collected supernatants were acidified with TFA ( $1 \%$ final concentration, $v /$ $v)$ and filtered $(0.45 \mu \mathrm{m}$ filter $)$. Aliquots $(30 \mu \mathrm{l})$ were analyzed using HPLC (Kromasil C4 column, $250 \times 4.6 \mathrm{~mm}$; Supelco) and the same buffers as those used during the purification procedure. The column was flushed for $5 \mathrm{~min}$ following injection at a constant concentration of $34 \% \mathrm{~B}$. A linear gradient from 34 to $100 \% \mathrm{~B}$ was then applied over $10 \mathrm{~min}$ at $1 \mathrm{ml} / \mathrm{min}$. Under these conditions, BacCH91 was detected at $220 \mathrm{~nm}$ as a single peak eluting with a retention time of $14.6 \mathrm{~min}$. The relative amount of bacteriocin was calculated as the area under the peak.

The residual proteolytic activity of collected culture media was determined at $37{ }^{\circ} \mathrm{C}$ using Hide Powder Azure (Calbiochem) in $0.1 \mathrm{M}$ Tris- $\mathrm{HCl}(\mathrm{pH} 7.5)$ supplemented with $5 \mathrm{mM}$ cysteine and $5 \mathrm{mM}$ EDTA.

\section{Determination of the bacteriocin coding sequence}

The coding sequence for BacCH91 and its flanking regions was determined using standard molecular biology methods (Sambrook et al. 1989). Briefly, the amino acid sequence of bacteriocin determined using Edman sequencing was compared with sequences in the National Center for Biotechnology Information (NCBI) database (http://www.ncbi.nlm.nih.gov), using the BLASTp algorithm. Based on the matching genomic sequences obtained, we designed a set of primers flanking the region of interest. Amplicons obtained by PCR using $S$. aureus CH-91 genomic DNA were cloned into pTZ57R/T (Fermentas). The plasmids were sequenced across the inserts. The contig sequence was edited using Genedoc 2.0 software (Nicholas et al. 1997) and deposited in the GenBank (accession number JQ655767).

\section{Determination of the distribution of the bacteriocin gene}

The distribution of the bacteriocin gene among the staphylococcal strains was determined using PCR. For PCR, the primers flanking the bacteriocin gene, i.e., bacteruniqueF (5'-TTAGTGAAAATAAATAGTA) and bacterrewR (5'CATTTGTAAGCACCTCAC), were used under the following PCR cycling conditions: 1 cycle at $94{ }^{\circ} \mathrm{C}$ for $2 \mathrm{~min}$, 30 cycles at $94{ }^{\circ} \mathrm{C}$ for $30 \mathrm{~s}, 42{ }^{\circ} \mathrm{C}$ for $30 \mathrm{~s}$, and $72{ }^{\circ} \mathrm{C}$ for $45 \mathrm{~s}$. Strains positive for $\mathrm{bacCH} 91$ were further assayed to assess the occurrence of the allelic variant of bac CH91. The PCR product was directly treated with the restriction enzyme BcuI (Fermentas). The restriction fragments were separated using $2 \%$ agarose gel electrophoresis. Restriction pattern I consisted of 271 and 128 bp products of a single cleavage, whereas restriction pattern II was characterized by an uncleaved amplicon of $399 \mathrm{bp}$.

\section{Results}

Purification and biochemical characterization of bacteriocin BacCH91

BacCH91 was purified from the culture supernatant of $S$. aureus $\mathrm{CH}-91$ using a three-stage procedure comprising precipitation with ammonium sulfate, extraction with organic solvents, and reversed-phase HPLC on a C8 column. Using the optimized gradient, the bacteriocin eluted at approximately $11.5 \mathrm{~min}$ (Fig. 1). The preparation obtained was homogenous, as evidenced by SDS-PAGE (Fig. 1), ESIMS, and N-terminal sequencing (data not shown). The purification procedure yielded $1 \mathrm{mg}$ purified $\mathrm{BacCH} 91$ from $1 \mathrm{~L}$ of culture supernatant (10\% overall yield; Table 1$)$.

Based on ESI-MS, the molecular mass of the purified bacteriocin was estimated at 2,074.9 $\mathrm{Da}$. Direct N-terminal Edman degradation allowed only partial determination of the first six residues: Ile-X-X-Phe-Ile-Gly, where X denotes an unknown residue. Identification of amino acid residues at positions 2, 3, 7, and subsequent positions was not possible in the standard setup, suggesting posttranslational modification of side chains or unusual intramolecular bonds, both of which commonly occur in lantibiotics. Identification of residues at positions $2,3,7$, and subsequent positions was possible only after the chemical derivatization of the bacteriocin with ethanethiol under alkaline conditions. The full 21-mer sequence of BacCH91 was found to be IlebmeSeCys-SeCys-Phe-Ile-Gly-SeCys-bmeSeCys-Pro-GlyX-Gly-Lys-bmeSeCys-Gly-SeCys-Phe-Asn-SeCys-PheSeCys, where $\mathrm{X}$ is an unknown residue, bmeSeCys is betamethyl-S-ethylcysteine (a reaction product of ethanethiol with 2,3-didehydro-2-aminobutyric acid or 3-methyllanthionine), and SeCys is S-ethyl-cysteine (a reaction product of ethanethiol with 2,3-didehydroalanine or lanthionine).

Antibacterial activity

The bactericidal activity of the purified BacCH91 was determined for a range of Gram-positive and Gram-negative bacteria using the micro-dilution assay. The bacteria tested included 11 strains of staphylococci, 7 strains of other Gram-positive bacteria, and 5 Gram-negative species (Table 2). With the exception of L. lactis, for which the determined MIC was over $100 \mu \mathrm{M}$, all the Gram-positive bacteria tested were susceptible to BacCH91. Among the microorganisms tested, M. luteus strains exhibited the highest susceptibility to the bacteriocin (2.5 and $40 \mathrm{nM}$ for DSMZ 20030 and CBM, respectively). For 


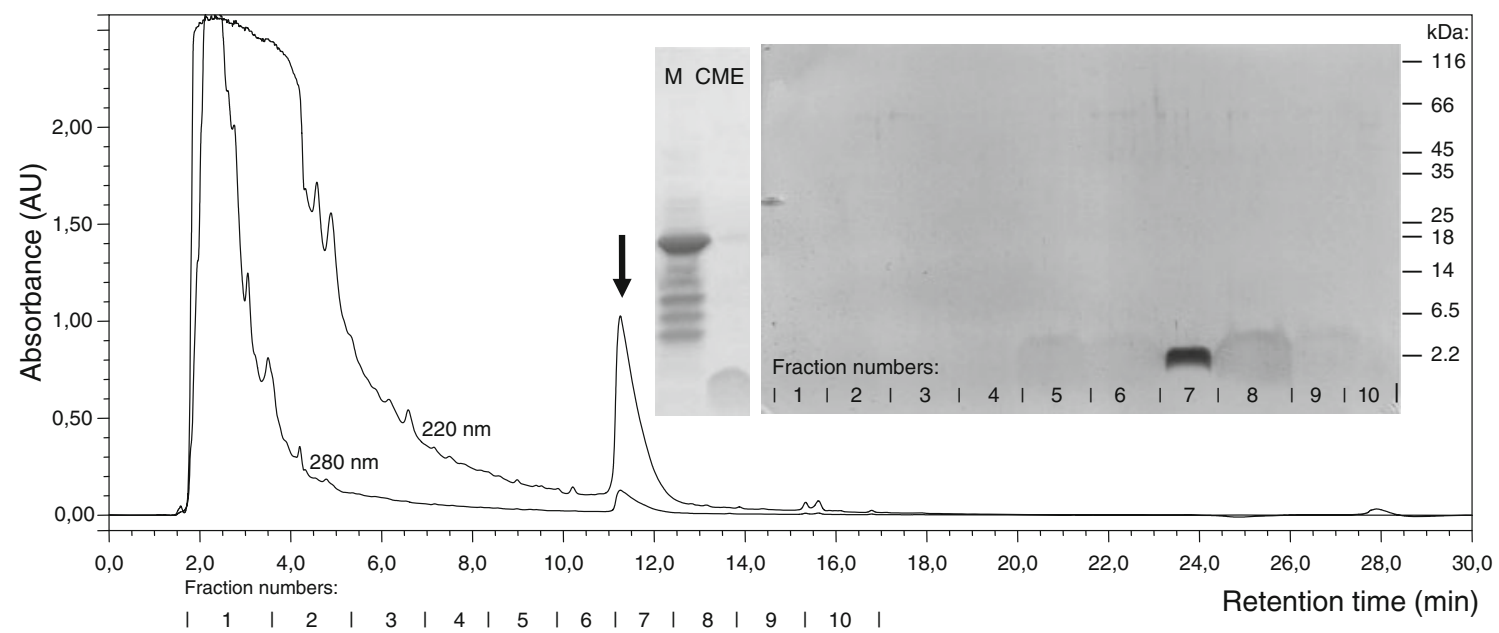

Fig. 1 HPLC purification of BacCH91. The chloroform/methanol extract of the precipitated culture medium was separated on a $\mathrm{C} 8$ column. The arrow indicates the homogenous bacteriocin peak. The

other Gram-positive bacteria, the MICs ranged from a $0.31 \mu \mathrm{M}$ for $S$. lutea to $6.0 \mu \mathrm{M}$ for various $S$. aureus strains. Interestingly, the bacteriocin-producing strain $S$. aureus $\mathrm{CH}-91$ was also susceptible to BacCH91 (MIC $1.3 \mu \mathrm{M}$ ). None of the Gramnegative species assayed were susceptible to BacCH91, even at the highest concentration tested $(100 \mu \mathrm{M})$.

Effect of $\mathrm{pH}$, temperature, and peptidases on BacCH91 activity

The effect of $\mathrm{pH}$ on the activity of BacCH91 was studied in the range $\mathrm{pH} 3-11$. Purified bacteriocin retained full bactericidal activity during incubation for $3 \mathrm{~h}$ at $\mathrm{pH} 3.0-6.0$ (Fig. 2b). Incubation at $\mathrm{pH} 7.0$ and higher $\mathrm{pH}$ values caused a gradual loss of bactericidal activity, and complete inactivation occurred at $\mathrm{pH} 11.0$.

The effect of temperature on the activity of BacCH91 was studied at $\mathrm{pH} 6.4$ and $\mathrm{pH}$ 7.4. The bacteriocin was incubated at $37,60,80$, and $99^{\circ} \mathrm{C}$, and the residual activity was determined using the radial diffusion assay and $S$. lutea as an indicator strain inserts contain the SDS-PAGE image of the culture medium $(M)$, chloroform/methanol extract $(C M E)$, and the respective fractions from the $\mathrm{C} 8$ column

(Fig. 2a). BacCH91 maintained its activity for $1 \mathrm{~h}$ at temperatures up to $80^{\circ} \mathrm{C}$. Even short incubation at $99^{\circ} \mathrm{C}$ or several hours of incubation at temperatures higher than $60^{\circ} \mathrm{C}$ resulted in complete inactivation of the bacteriocin. The temperature-induced inactivation was associated with hydrolysis of the polypeptide chain as evidenced by HPLC and ESI-MS analyses (not shown).

The susceptibility of BacCH91 to proteolysis was studied at $\mathrm{pH} 6.4$ and at the optimum $\mathrm{pH}$ for each of the enzymes tested. Following incubation with each enzyme, the residual bactericidal activity was determined using the radial diffusion assay, and the integrity of BacCH91 was analyzed using HPLC. None of the proteases tested (see "Materials and methods" section) affected the activity or integrity of BacCH91, including all of the staphylococcal extracellular peptidases tested.

Influence of StpC on the biosynthesis and stability of BacCH91

S. aureus strain CH-91 secretes large quantities of cysteine peptidase StpC, an enzyme that constitutes the major component

Table 1 Summary of the purification process of BacCH91 bacteriocin

\begin{tabular}{|c|c|c|c|c|c|c|c|}
\hline Stage of purification & $\begin{array}{l}\text { Fraction } \\
\text { volume (ml) }\end{array}$ & $\begin{array}{l}\text { Protein } \\
\text { concentration }^{\mathrm{a}} \\
(\mathrm{mg} / \mathrm{ml})\end{array}$ & $\begin{array}{l}\text { Total } \\
\text { protein }^{\mathrm{a}}(\mathrm{mg})\end{array}$ & $\begin{array}{l}\text { Specific activity } \\
(\mathrm{U} / \mathrm{mg})\end{array}$ & $\begin{array}{l}\text { Total } \\
\text { activity }^{\mathrm{b}}(\mathrm{U})\end{array}$ & $\begin{array}{l}\text { Yield } \\
(\%)\end{array}$ & $\begin{array}{l}\text { Purification } \\
\text { factor (fold) }\end{array}$ \\
\hline Culture supernatant & 500 & 5.65 & 2,825 & 19.35 & 54,664 & 100 & 1 \\
\hline $\begin{array}{l}\text { Ammonium sulfate } \\
\text { precipitation }\end{array}$ & 29.9 & 7.65 & 228.7 & 55.99 & 12,805 & 23.4 & 2.89 \\
\hline Organic extract & 3.85 & 17.0 & 65.5 & 92.08 & 6,031 & 11.0 & 4.76 \\
\hline HPLC & 1 & 0.548 & 0.548 & 10,220 & 5,600 & 10.2 & 528 \\
\hline
\end{tabular}

${ }^{\mathrm{a}}$ The protein concentration was routinely determined using the BCA. Only for the final peptide preparation (following HPLC) was the concentration measured by amino acid analysis

${ }^{\mathrm{b}}$ One unit of bactericidal activity (units) was arbitrarily defined as the amount of bacteriocin resulting in an inhibition zone of $1 \mathrm{~cm}$ diameter, as determined in the radial diffusion assay 
Table 2 Antibacterial activity (MIC) of BacCH91 towards selected Gram-positive and Gram-negative strains

\begin{tabular}{|c|c|}
\hline Strain & $\mathrm{MIC}(\mu \mathrm{M})$ \\
\hline Bacillus licheniformis NCTC 7224 & 1.8 \\
\hline Bacillus subtilis ATCC 6633 & 2.6 \\
\hline Lactococcus lactis subsp. lactis LOCK 0869 & $>100$ \\
\hline Micrococcus luteus DSMZ 20030 & 0.0025 \\
\hline Micrococcus luteus CBM & 0.04 \\
\hline Sarcina lutea ATCC 9341 & 0.31 \\
\hline Staphylococcus aureus ATCC 25923 & 6.0 \\
\hline Staphylococcus aureus $\mathrm{CH} 91^{\mathrm{a}}$ & 1.3 \\
\hline Staphylococcus aureus M-122 & 4.0 \\
\hline Staphylococcus aureus Newman ${ }^{\mathrm{a}}$ & 6.0 \\
\hline Staphylococcus aureus RN4220 ${ }^{\mathrm{a}}$ & 6.0 \\
\hline Staphylococcus epidermidis ATCC 35347 & 1.6 \\
\hline Staphylococcus intermedius ATCC 29663 & 1.6 \\
\hline Staphylococcus pseudintermedius LMG 22219 & 1.5 \\
\hline Staphylococcus saprophiticus ATCC 49453 & 3.0 \\
\hline Staphylococcus xylosus $\mathrm{kw} 2,5^{\mathrm{b}}$ & $1.5-2.0$ \\
\hline Streptococcus mutans ATCC 25175 & 2.0 \\
\hline Streptococcus pneumoniae ATCC 49619 & 1.6 \\
\hline Escherichia coli K12 ATCC 10798 & $>100$ \\
\hline Klebsiella pneumoniae & $>100$ \\
\hline Pseudomonas aeruginosa ATCC 27853 & $>100$ \\
\hline Serratia marcescens & $>100$ \\
\hline Sphingomonas sp. AMC 3962 & $>100$ \\
\hline
\end{tabular}

${ }^{\mathrm{a}}$ Bacteriocin gene positive strain

${ }^{\mathrm{b}}$ Two representative strains from a single herd were tested

of the extracellular, soluble proteome of the bacterium (Wladyka et al. 2011b). It was therefore of interest to determine the effect of the enzyme on the biosynthesis and stability of BacCH91 in vivo. The bacteria were cultured in liquid medium in the presence of E64, a specific irreversible inhibitor of cysteine peptidases. Samples of the culture medium were collected after 5,10 , and $24 \mathrm{~h}$, and the amount of bacteriocin was estimated by HPLC. The amount of BacCH91 was the same for all concentrations of the E-64 tested $(0.01,0.1$, and $1.0 \mathrm{mM})$ and in the control medium (no inhibitor added). StpC inhibition was tested in parallel using the chromogenic protein substrate. No residual proteolytic activity was detected in the culture media containing the inhibitor, thereby confirming its effectiveness. This experiment indicated that $\mathrm{StpC}$ is dispensable for posttranslational maturation of BacCH91 and confirmed that the peptidase does not affect the stability of the lantibiotic.

Characterization of the gene encoding BacCH91 and its localization in the staphylococcal genome

The sequence of BacCH91 obtained using Edman degradation was aligned with staphylococcal genomic data using the
BLASTp algorithm in the NCBI database. An open reading frame (ORF) encoding an identical sequence was identified in three $S$. aureus strains (RF122, LGA 251, and ED133), all of which were isolated from animals. Additional matches of lesser similarity (but differing only at several positions) were identified in strains of human origin, but also in RF122, LGA 251, and ED133, indicating the presence of two genes encoding similar bacteriocins in the genomes of some $S$. aureus strains. The sequence encoding BacCH91 is not present in the genome of strain ED98, which was isolated from chicken, or other sequenced $S$. aureus genomes. This indicates that the bacCH91 gene is not a part of the core genome but rather a part of an accessory genetic pool.

To determine the precise location and neighborhood of bacCH91 in the genetic material of $S$. aureus $\mathrm{CH}-91$, a 2-kbp fragment flanking the gene was amplified and sequenced. The analysis of the obtained sequence demonstrated that the gene encoding leukotoxin D (lukD) was located 861 nucleotides upstream of $b a c C H 91$, while $l b p B$, a gene coding for a lantibiotic biosynthesis protein $\mathrm{B}$, was located 64 nucleotides downstream of bacCH91 (Fig. 3). Although the neighborhood of bacCH91 resembles that of the other staphylococcal bacteriocins identified during this study and described in the published staphylococcal genomes, significant differences were also found. Other staphylococcal lantibiotic gene clusters encode two very similar bacteriocins, whereas only a single gene ( $\mathrm{acCH}$ C1) was present in $\mathrm{S}$. aureus CH-91 (Fig. 3a). Moreover, a sequence with no homology to any database sequence was found downstream of lukD in strain CH-91. This sequence was approximately $200 \mathrm{bp}$ long and ended with 13-nucleotide inverted repeats. Downstream of this sequence in strain CH-91, instead of the bacl lantibiotic gene found in the other strains of staphylococci, we identified an ORF (hyp) that encodes an 86-amino acid polypeptide having moderate homology to the $\mathrm{C}$-terminal part of the staphylococcal IstB-like ATP-binding protein followed by bacCH91 (a bac2 homologue). Downstream of bacCH91, an 11-nucleotide perfect IR identical to that found downstream of $b a c 2$ in the other strains was identified.

Occurrence of the lantibiotic gene allele in S. aureus strains

Analysis of available genomic data revealed that bacCH91 homologues ( $b a c 2)$ occur in two conserved allelic variants (Fig. 3 and ESM Fig. S1). A lantibiotic gene identical to that of strain CH-91 was found in only three strains of $S$. aureus (RF122, LGA 251, and ED133), all of which were isolated from cows, whereas neither $b a c 1$ nor $b a c 2$ was present in the ED98 strain, which is of chicken origin. An allelic variant of $b a c 2$ was identified in some strains isolated from humans (other human strains had neither bac1 nor bac2). The identified alleles of $b a c 2$ differ in the presence of a $B c u I$ (SpeI) site, which conveniently facilitated identification 
Fig. 2 Temperature and $\mathrm{pH}$ stability of BacCH91. a Residual bactericidal activity of bacteriocin following treatment for the indicated times at the indicated temperatures and $\mathrm{pH}$. b Residual bactericidal activity $3 \mathrm{~h}$ following bacteriocin exposure to buffers of the indicated $\mathrm{pH}$. A radial diffusion assay with the $S$. lutea indicator strain was used to determine the residual bactericidal activity. For other experimental details, see "Materials and methods" section

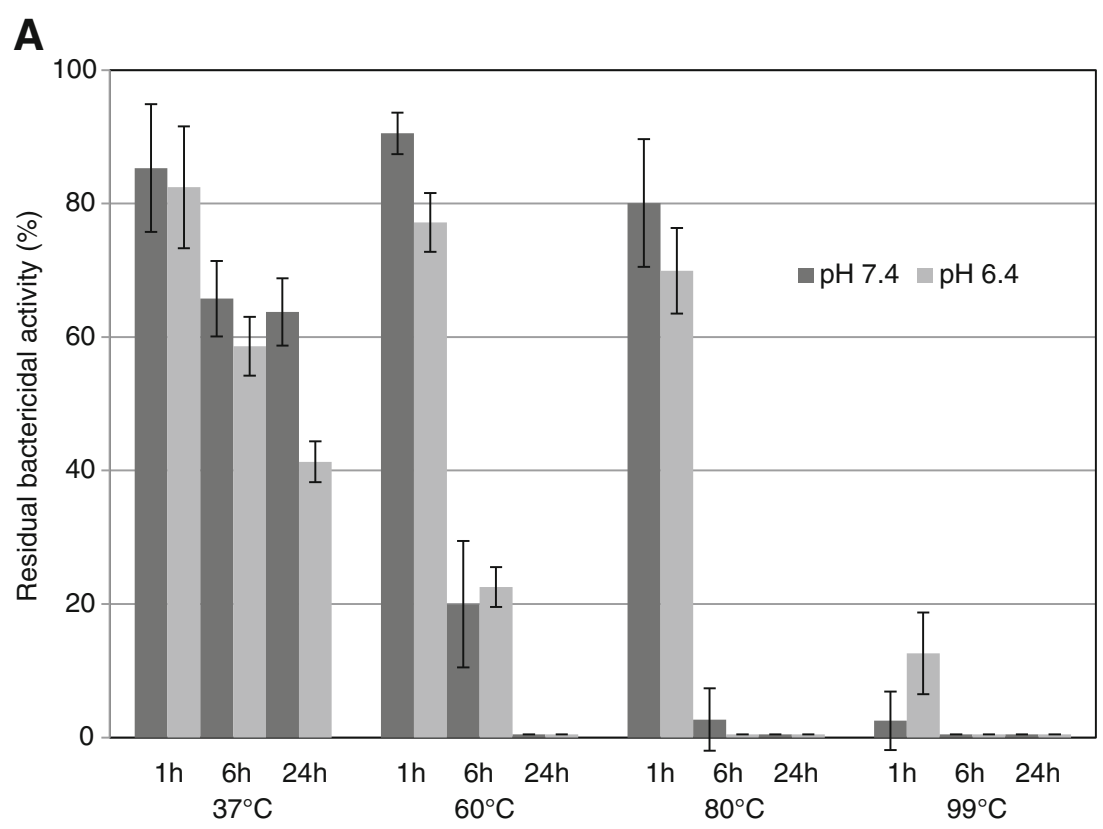

B

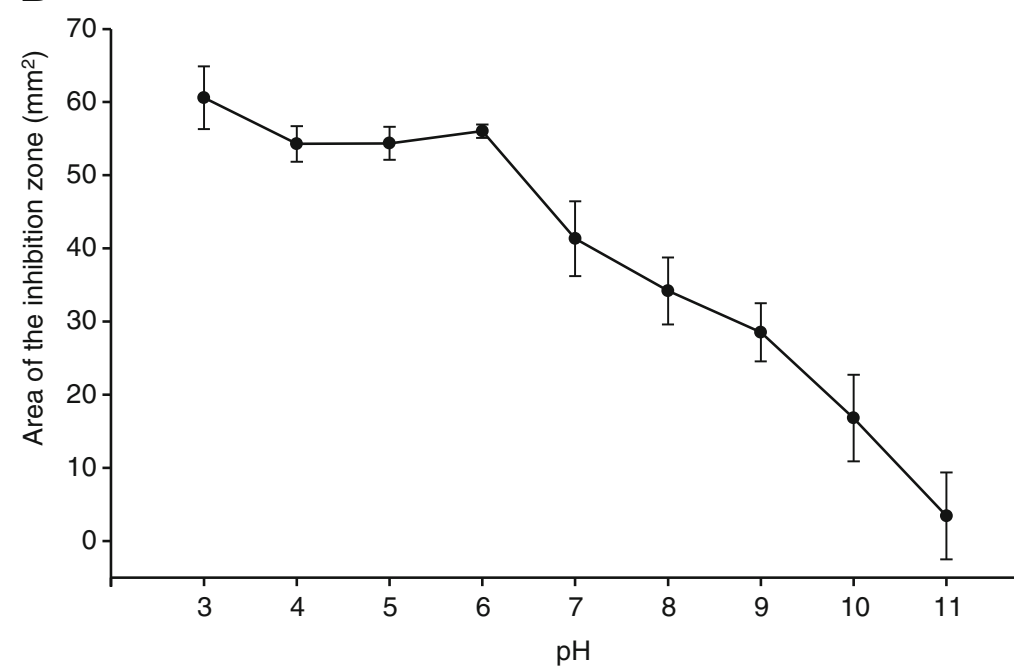

using restriction fragment length polymorphism (RFLP) analysis (Fig. 3b, c). To assess the general occurrence of allelic variants, $58 \mathrm{~S}$. aureus strains were tested, including 21 of human origin and 37 isolated from animals. PCR products (399 bp) containing the lantibiotic gene (Fig. 3b), obtained using the bacteruniqueF and bacterrew $\mathrm{R}$ primers, were treated with $B c u I$, and the restriction products were analyzed using electrophoresis. A total of 23 strains (11 of human origin and 12 of animal origin) were positive for the bac2 gene (Table 3 and ESM Table S1). The type I restriction pattern characteristic of strain $\mathrm{CH}-91$ was found in 8 of the 12 bacteriocin-positive strains isolated from animals but in none of the 11 bacteriocin-positive strains of human origin. With respect to the strains isolated from poultry, 9 of the 20 strains were positive for the lantibiotic gene, with seven strains exhibiting a type I restriction pattern. It is noteworthy that the two remaining strains with a type II restriction pattern were MRSA strains, while all the other poultry strains were MSSA.

\section{Discussion}

The BacCH91 reported here is the first AI-type lantibiotic isolated from $S$. aureus and thoroughly characterized. Existence of a gene coding for similar bacteriocin was previously reported (Daly et al. 2010), but the described properties of a corresponding peptide were questioned by Joo et al. (2011). The former authors claimed to have identified a respective peptide in culture supernatants of $S$. aureus based on mass spectrometry data. The identification was however doubtful (2 Da molecular weight disagreement), and afterwards, Joo 
A.

CH91
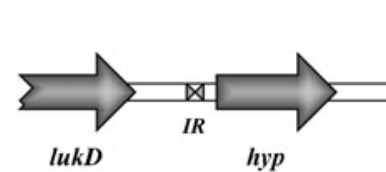

$\stackrel{F}{\rightarrow}$
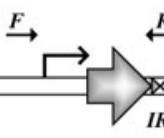

$\stackrel{R}{\leftarrow}$

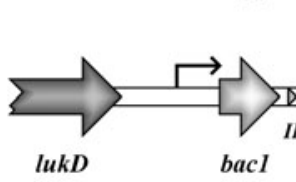

bacl

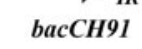

others

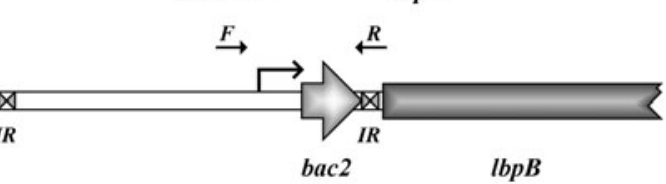

C.

\section{CH91}

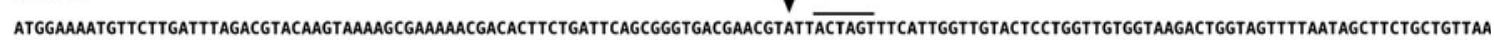

M E N V L D L D V
B.

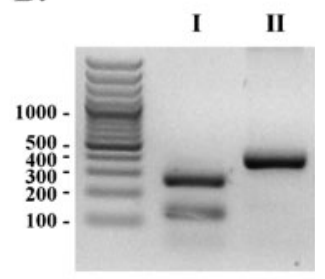

Fig. 3 Chromosome organization in the vicinity of the bacCH91 gene. a Schematic organization of the chromosome region containing the bacteriocin gene in $S$. aureus $\mathrm{CH}-91$ and other $S$. aureus strains. Note: some strains were devoid of bacteriocin genes and the entire region downstream of $l u k D$ was organized very differently, which is not shown here. ORFs are shadowed gray. Putative promoter regions are indicated with the bent arrows. The primers used for amplification of

and collaborators noticed that the molecular mass of the antimicrobial agent identified by Daly was in perfect agreement with proteolytically processed phenol soluble modulin, also exhibiting pronounced antimicrobial activity. Therefore, the identity of the antimicrobial agent characterized by Daly and colleagues remains uncertain.

The BacCH91 bacteriocin was purified from culture supernatants of strain $\mathrm{CH}-91$ using a procedure originally designed for bacterial hemolytic peptides (Mak et al. 2008). The relatively hydrophobic character of the peptide facilitated effective extraction using an optimized mixture of organic solvents, and a single subsequent chromatography step (reversed-phase HPLC) produced a homogenous bacteriocin preparation. This procedure is much less timeconsuming than the procedures that have been used by others to purify similar peptides. Although the yield $(10 \%)$ was not as high as that reported for some bacteriocins (e.g., $19 \%$ for staphylococcin T), it was still higher than that reported for other bacteriocin isolation procedures (e.g., $1 \%$ for mutacin B-Ny266) (Furmanek et al. 1999; Mota-Meira et al. 1997). Determination of the amino acid sequence of BacCH91 using Edman degradation required the bacteriocin allele are indicated by straight arrows. Inverted repeats are indicated by "IR" and a double triangle symbol. b Agarose gel showing an example RFLP result for two allelic variants of the bacCH91 (bac2) gene. c Nucleotide and amino acid sequence of the pre-peptide of BacCH91. An arrowhead indicates the beginning of the mature form. The line above the sequence indicates the cleavage site for $B c u I$, which was used for determining the allelic variants

chemical modification of multiple residues, as previously reported for other lantibiotics (Meyer et al. 1994). The results of chemical sequencing were confirmed by cloning of the bacteriocin gene. Based on the sequence obtained, BacCH91 was classified in the epidermin group of AI-type lantibiotics, which includes peptide epidermin; Val1-Leu6epidermin; gallidermin; staphylococcin T; mutacins BNy266, 1140, I and III; and streptin (Bierbaum and Sahl 2009; Chatterjee et al. 2005). BacCH91 is most closely related to epidermin and gallidermin (Fig. 4). Significantly, the fourth residue was phenylalanine in $\mathrm{BacCH} 91$ but lysine in both epidermin and gallidermin, which explains the more hydrophobic character of BacCH91.

The MICs of BacCH91 for various bacterial species clearly demonstrated that the bacteriocin was effective only against Gram-positive microorganisms, however not against L. lactis. Among the species tested, M. luteus exhibited the highest susceptibility to BacCH91. The MIC determined for this species (2.5 nM for the strain DSMZ 20030 and $40 \mathrm{nM}$ for the strain $\mathrm{CBM}$ ) is comparable with the value obtained for closely related galidermin (Ottenwalder et al. 1995), which indicates that at least one likely target bacterial
Table 3 Occurrence of allelic variants of the bacteriocin gene among $S$. aureus strains

${ }^{\text {a }}$ Percent of bacteriocin gene positive strains among all tested strains

${ }^{\mathrm{b}}$ Percent of the respective restriction pattern among bacteriocin gene positive strains

\section{Strain origin S. aureus strain Detectable bacteriocin gene Restriction pattern}

\begin{tabular}{lllll}
\hline I & & & II \\
\cline { 1 - 1 } \cline { 5 - 5 } Quantity & $\%$ & & Quantity & $\%$ \\
\hline 0 & 0 & 11 & 100 \\
7 & 77.8 & 2 & 22.2 \\
1 & 33.3 & 2 & 66.6 \\
8 & $34.8^{\mathrm{b}}$ & 15 & $65.2^{\mathrm{b}}$
\end{tabular}


BacCH91 ITSFIGCTPGCGKTGSFNSFCC

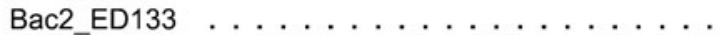

Bac2_Newman .. HS L...........

Bac1_ED133 ... HFL. SF .........

Bac1_Newman ... HLF.SF . E . . . . . .

Gälidermin . A. KF L . . . A . . . . Y . .

Staphylococcin_T. A. KF L . . . A . . . . . Y . . Epidermin . A.KF I.... A.....Y..

[Val1-Leu6]-Epidermin VA. KF . . . . A . . . . Y . .

Mutacin_B-Ny266 F K.WS F .... A . . . . Y . . Mutacin_1140 F K.WS L . . . . AR . . . . Y . . Conservation $0 \%$

Fig. 4 Alignment of the amino acid sequences of AI-type lantibiotics. Identical residues are indicated by dots

species has been identified. The high susceptibility of $M$. luteus to bacteriocin produced by $S$. aureus has possible biological relevance since both bacteria are residents of mammalian skin and nasal mucosa. Therefore, it is likely that the bacteriocin-producing staphylococcal strains have an advantage in competing for the same ecological niche with Micrococcus sp. The MIC values for Staphylococcus spp. did not differ significantly among species and strains, and they were most comparable to the MIC for $S$. aureus strain $\mathrm{CH}-91$. This indicates that BacCH91 action is not directed against other, non-bacteriocin-producing staphylococcal strains.

No differences in the temperature stability of BacCH91 were observed between neutral $\mathrm{pH}$ and $\mathrm{pH}$ 6.4, which is typical of chicken skin (Bhaduri and Cottrell 2004). Similarly to other lantibiotics, the bacteriocin from $S$. aureus strain CH-91 was stable at elevated temperatures (almost $100 \%$ activity was retained during incubation for $1 \mathrm{~h}$ at $80^{\circ}$ C) and resistant to proteolytic inactivation. The bacteriocin was not affected by any of the staphylococcal peptidases tested, particularly StpC, which is abundantly produced by strain CH-91. This was expected as it was assumed that secretory peptides would not be inactivated by proteases secreted by the same microorganism into the same environmental niche. Surprisingly, BacCH91 was unaffected by trypsin and proteinase $\mathrm{K}$. This result differs from that obtained in previous studies of AI-type epidermin-like and nisin-like lantibiotics which are typically cleaved by trypsin, although only after prolonged incubation (Kellner et al. 1988; Kuipers et al. 1993).

Lantibiotics are ribosomally synthesized peptides that undergo extensive posttranslational modification, including proteolytic processing of the leader peptide. It has been demonstrated that as many as three extracellular peptidases (subtilisin, WprA, and Vpr) are involved in maturation of subtilin, produced by B. subtilis ATCC 6633 (Corvey et al. 2003). Other antimicrobial peptides require activation by endogenous extracellular peptidases (Faye et al. 2002).
Since BacCH91 is produced by a highly proteolytic strain, it was important to assess whether StpC, the major extracellular peptidase of strain $\mathrm{CH}-91$, is engaged in maturation of bacteriocin. Inhibition of StpC activity during bacterial growth using a specific irreversible inhibitor of cysteine peptidases (E-64) had no effect on the level of BacCH91, suggesting an StpCindependent maturation mechanism. This finding is consistent with the recently reported substrate specificity of StpC for bulky uncharged amino acid residues (Kalinska et al. 2012); in turn, the BacCH91 leader peptide is processed after a charged residue (Fig. 3c).

Since BacCH91 is the first AI-type lantibiotic characterized from $S$. aureus, we assessed whether identical or homologous lantibiotics were present in other strains. The database search revealed that a gene encoding an identical bacteriocin was present in $S$. aureus strains isolated from cows. Moreover, highly homologous genes were found in some strains of human origin, whereas many strains of both human and animal origin completely lacked genes homologous to bacCH91. Therefore, it was concluded that bacCH91 is accessory to the core genome of staphylococci. This is of particular importance since accessory genetic material has been implicated in virulence and host specificity of staphylococci (Lowder et al. 2009). The genomic localization of bacCH91 contrasts with other identified staphylococcal bacteriocin genes, which are all located on plasmids (Bierbaum et al. 1996). Analysis of staphylococcal genomic data demonstrated that bacteriocins identical or closely related to BacCH91 were encoded in tandem repeats (Daly et al. 2010). Only strain CH-91 exhibited unique organization of the region involved, with only a single bacCH91 gene being present, while the second bacteriocin gene was substituted by an ORF encoding a polypeptide similar to proteins that are thought to be involved in recombination of genetic material (Solinas et al. 1995; Fig. 3a). This indirectly suggests the origin of the observed genetic rearrangement. In all the cases, the gene encoding a lantibiotic biosynthesis protein ( $\mathrm{LbpB}$ ) was located downstream of bacCH91 (bac2). This organization is comparable to that of a cluster of genes driving the biosynthesis of the homologous lantibiotic epidermin, produced by $S$. epidermidis DSM 3095 (Schnell et al. 1992).

It was demonstrated that bacCH91 occurred in two allelic variants distinguishable by RFLP. The allelic variant I identified in $S$. aureus $\mathrm{CH}-91$ was characteristic for the strains of poultry origin and was not present in any of the strains of human origin tested. The isolates of human origin were characterized by allelic variant II, which was also detected in several strains of animal origin. Therefore, the simple RFLP assay may serve as a useful tool for tracing the transmission of staphylococcal strains among hosts. 
Acknowledgments The authors thank S. Takeuchi, R. Fitzgerald, and J. Miedzobrodzki for providing bacterial strains, and M. Rozalska for helpful comments. The study was supported in part by grant $\mathrm{N}$ N303 813340 (to BW) from the National Science Center, Krakow, Poland. The research was carried out with equipment obtained with support of European Union structural funds (grants POIG.02.01.00-12064/08 and POIG.02.01.00-12-167/08).

Open Access This article is distributed under the terms of the Creative Commons Attribution License which permits any use, distribution, and reproduction in any medium, provided the original author(s) and the source are credited.

\section{References}

Bhaduri S, Cottrell B (2004) Survival of cold-stressed Campylobacter jejuni on ground chicken and chicken skin during frozen storage. Appl Environ Microbiol 70:7103-7109

Bierbaum G, Sahl HG (2009) Lantibiotics: mode of action, biosynthesis and bioengineering. Curr Pharm Biotechnol 10:2-18

Bierbaum G, Gotz F, Peschel A, Kupke T, van de Kamp M, Sahl HG (1996) The biosynthesis of the lantibiotics epidermin, gallidermin, Pep5 and epilancin K7. Antonie Van Leeuwenhoek 69:119-127

Chatterjee C, Paul M, Xie L, van der Donk WA (2005) Biosynthesis and mode of action of lantibiotics. Chem Rev 105:633-684

CLSI (2006) Methods for dilution antimicrobial susceptibility tests for bacteria that grow aerobically; approved standard - seventh edition. Clinical and Laboratory Standards Institute, Wayne, PA, USA

Corvey C, Stein T, Dusterhus S, Karas M, Entian KD (2003) Activation of subtilin precursors by Bacillus subtilis extracellular serine proteases subtilisin (AprE), WprA, and Vpr. Biochem Biophys Res Commun 304:48-54

Crupper SS, Gies AJ, Iandolo JJ (1997) Purification and characterization of staphylococcin BacR1, a broad-spectrum bacteriocin. Appl Environ Microbiol 63:4185-4190

Daly KM, Upton M, Sandiford SK, Draper LA, Wescombe PA, Jack RW, O'Connor PM, Rossney A, Gotz F, Hill C, Cotter PD, Ross RP, Tagg JR (2010) Production of the Bsa lantibiotic by communityacquired Staphylococcus aureus strains. J Bacteriol 192:1131-1142

Devriese LA, Vancanneyt M, Baele M, Vaneechoutte M, De Graef E, Snauwaert C, Cleenwerck I, Dawyndt P, Swings J, Decostere A, Haesebrouck F (2005) Staphylococcus pseudintermedius sp. nov., a coagulase-positive species from animals. Int J Sys Evol Microbiol 55:1569-1573

Dinges MM, Orwin PM, Schlievert PM (2000) Exotoxins of Staphylococcus aureus. Clin Microbiol Rev 13:16-34

Dziga D, Wladyka B, Zielinska G, Meriluoto J, Wasylewski M (2012) Heterologous expression and characterisation of microcystinase. Toxicon 59:578-586

Faye T, Brede DA, Langsrud T, Nes IF, Holo H (2002) An antimicrobial peptide is produced by extracellular processing of a protein from Propionibacterium jensenii. J Bacteriol 184:3649-3656

Foster TJ (2005) Immune evasion by staphylococci. Nat Rev Microbiol 3:948-958

Furmanek B, Kaczorowski T, Bugalski R, Bielawski K, Bohdanowicz J, Podhajska AJ (1999) Identification, characterization and purification of the lantibiotic staphylococcin $\mathrm{T}$, a natural gallidermin variant. J Appl Microbiol 87:856-866

Galvez A, Abriouel H, Lopez RL, Ben Omar N (2007) Bacteriocin-based strategies for food biopreservation. Int J Food Microbiol 120:51-70

Gillor O, Ghazaryan L (2007) Recent advances in bacteriocin application as antimicrobials. Recent Pat Antiinfect Drug Discov 2:115122
Heidrich C, Pag U, Josten M, Metzger J, Jack RW, Bierbaum G, Jung G, Sahl HG (1998) Isolation, characterization, and heterologous expression of the novel lantibiotic epicidin 280 and analysis of its biosynthetic gene cluster. Appl Environ Microbiol 64:3140-3146

Herron-Olson L, Fitzgerald JR, Musser JM, Kapur V (2007) Molecular correlates of host specialization in Staphylococcus aureus. PLoS One 2:e1120

Joo HS, Cheung GY, Otto M (2011) Antimicrobial activity of community-associated methicillin-resistant Staphylococcus aureus is caused by phenol-soluble modulin derivatives. J Biol Chem 286:8933-8940

Kaletta C, Entian KD, Kellner R, Jung G, Reis M, Sahl HG (1989) Pep5, a new lantibiotic: structural gene isolation and prepeptide sequence. Arch Microbiol 152:16-19

Kalinska M, Kantyka T, Greenbaum DC, Larsen KS, Wladyka B, Jabaiah A, Bogyo M, Daugherty PS, Wysocka M, Jaros M, Lesner A, Rolka K, Schaschke N, Stennicke H, Dubin A, Potempa J, Dubin G (2012) Substrate specificity of Staphylococcus aureus cysteine proteasesstaphopains A, B and C. Biochimie 94:318-327

Kellner R, Jung G, Horner T, Zahner H, Schnell N, Entian KD, Gotz F (1988) Gallidermin: a new lanthionine-containing polypeptide antibiotic. Eur J Biochem 177:53-59

Kim PI, Sohng JK, Sung C, Joo HS, Kim EM, Yamaguchi T, Park D, Kim BG (2010) Characterization and structure identification of an antimicrobial peptide, hominicin, produced by Staphylococcus hominis MBBL 2-9. Biochem Biophys Res Commun 399:133-138

Kuipers OP, Rollema HS, de Vos WM, Siezen RJ (1993) Biosynthesis and secretion of a precursor of nisin $\mathrm{Z}$ by Lactococcus lactis, directed by the leader peptide of the homologous lantibiotic subtilin from Bacillus subtilis. FEBS Lett 330:23-27

Kuramasu S, Imamura Y, Takizawa T, Oguchi F, Tajima Y (1967) Studies on staphylococcosis in chickens. I. Outbreaks of staphylococcal infection on poultry farms and characteristics of Staphylococcus aureus isolated from chickens. Zentralbl Veterinarmed B 14:646-656

Lemos Miguel MA, Dias de Castro AC, Ferreira Gomes Leite S (2008) Inhibition of vancomycin and high-level aminoglycoside-resistant enterococci strains and Listeria monocytogenes by bacteriocinlike substance produced by Enterococcus faecium E86. Curr Microbiol 57:429-436

Lowder BV, Guinane CM, Ben Zakour NL, Weinert LA, ConwayMorris A, Cartwright RA, Simpson AJ, Rambaut A, Nubel U, Fitzgerald JR (2009) Recent human-to-poultry host jump, adaptation, and pandemic spread of Staphylococcus aureus. Proc Natl Acad Sci U S A 106:19545-19550

Mak P, Maszewska A, Rozalska M (2008) The amino acid sequences and activities of synergistic hemolysins from Staphylococcus cohnii. FEMS Microbiol Lett 287:230-235

Meyer HE, Heber M, Eisermann B, Korte H, Metzger JW, Jung G (1994) Sequence analysis of lantibiotics: chemical derivatization procedures allow a fast access to complete Edman degradation. Anal Biochem 223:185-190

Mota-Meira M, Lacroix C, LaPointe G, Lavoie MC (1997) Purification and structure of mutacin B-Ny266: a new lantibiotic produced by Streptococcus mutans. FEBS Lett 410:275-279

Navaratna MA, Sahl HG, Tagg JR (1998) Two-component antiStaphylococcus aureus lantibiotic activity produced by Staphylococcus aureus C55. Appl Environ Microbiol 64:4803-4808

Netz DJ, Sahl HG, Marcelino R, dos Santos Nascimento J, de Oliveira SS, Soares MB, do Carmo de Freire Bastos M (2001) Molecular characterisation of aureocin A70, a multi-peptide bacteriocin isolated from Staphylococcus aureus. J Mol Biol 311:939-949

Netz DJ, Pohl R, Beck-Sickinger AG, Selmer T, Pierik AJ, Bastos Mdo C, Sahl HG (2002) Biochemical characterisation and genetic analysis of aureocin A53, a new, atypical bacteriocin from Staphylococcus aureus. J Mol Biol 319:745-756 
Nicholas KB, Nicholas HB, Deerfield DW (1997) GeneDoc: analysis and visualization of genetic variation. EMBNET.NEWS 4:1-4

Ottenwalder B, Kupke T, Brecht S, Gnau V, Metzger J, Jung G, Gotz F (1995) Isolation and characterization of genetically engineered gallidermin and epidermin analogs. Appl Environ Microbiol 61:3894-3903

Polakowska K, Lis M, Helbin WM, Dubin G, Dubin A, Niedziolka J, Miedzobrodzki J, Wladyka B (2012) Virulence in chicken embryos but not nematode model correlates with a genetic background of Staphylococcus aureus strains. Microbes Infect 14:1352-1362

Postma B, Poppelier MJ, van Galen JC, Prossnitz ER, van Strijp JA, de Haas CJ, van Kessel KP (2004) Chemotaxis inhibitory protein of Staphylococcus aureus binds specifically to the C5a and formylated peptide receptor. J Immunol 172:6994-7001

Sambrook J, Fritsch EF, Maniatis T (1989) Molecular cloning: a laboratory manual. Cold Spring Harbor Laboratory Press, New York

Sandiford S, Upton M (2011) Identification, characterisation and recombinant expression of epidermicin NI01, a novel unmodified bacteriocin produced by Staphylococcus epidermidis displaying potent activity against staphylococci. Antimicrob Agents Chemother 56:1539-1547

Sashihara T, Kimura H, Higuchi T, Adachi A, Matsusaki H, Sonomoto K, Ishizaki A (2000) A novel lantibiotic, nukacin ISK-1, of Staphylococcus warneri ISK-1: cloning of the structural gene and identification of the structure. Biosci Biotechnol Biochem 64:2420-2428

Schagger H, von Jagow G (1987) Tricine-sodium dodecyl sulfatepolyacrylamide gel electrophoresis for the separation of proteins in the range from 1 to $100 \mathrm{kDa}$. Anal Biochem 166:368-379

Schnell N, Entian KD, Schneider U, Gotz F, Zahner H, Kellner R, Jung G (1988) Prepeptide sequence of epidermin, a ribosomally synthesized antibiotic with four sulphide-rings. Nature 333:276-278
Schnell N, Engelke G, Augustin J, Rosenstein R, Ungermann V, Gotz F, Entian KD (1992) Analysis of genes involved in the biosynthesis of lantibiotic epidermin. Eur J Biochem 204:57-68

Solinas F, Marconi AM, Ruzzi M, Zennaro E (1995) Characterization and sequence of a novel insertion sequence, IS1162, from Pseudomonas fluorescens. Gene 155:77-82

Takeuchi S, Kinoshita T, Kaidoh T, Hashizume N (1999) Purification and characterization of protease produced by Staphylococcus aureus isolated from a diseased chicken. Vet Microbiol 67:195-202

Takeuchi S, Matsunaga K, Inubushi S, Higuchi H, Imaizumi K, Kaidoh $\mathrm{T}$ (2002) Structural gene and strain specificity of a novel cysteine protease produced by Staphylococcus aureus isolated from a diseased chicken. Vet Microbiol 89:201-210

van de Kamp M, van den Hooven HW, Konings RN, Bierbaum G, Sahl HG, Kuipers OP, Siezen RJ, de Vos WM, Hilbers CW, van de Ven FJ (1995) Elucidation of the primary structure of the lantibiotic epilancin K7 from Staphylococcus epidermidis K7. Cloning and characterisation of the epilancin-K7-encoding gene and NMR analysis of mature epilancin K7. Eur J Biochem 230:587-600

Wang R, Braughton KR, Kretschmer D, Bach TH, Queck SY, Li M, Kennedy AD, Dorward DW, Klebanoff SJ, Peschel A, DeLeo FR, Otto M (2007) Identification of novel cytolytic peptides as key virulence determinants for community-associated MRSA. Nat Med 13:1510-1514

White JA, Hart RJ, Fry JC (1986) An evaluation of the Waters Pico-Tag system for the amino-acid analysis of food materials. J Automat Chem 8:170-177

Wladyka B, Dubin G, Dubin A (2011a) Activation mechanism of thiol protease precursor from broiler chicken specific Staphylococcus aureus strain CH-91. Vet Microbiol 147:195-199

Wladyka B, Kozik AJ, Bukowski M, Rojowska A, Kantyka T, Dubin G, Dubin A (2011b) alpha1-Antichymotrypsin inactivates staphylococcal cysteine protease in cross-class inhibition. Biochimie 93:948-953 